\title{
A Novel Teaching Strategy for Professional English Course for Automation Bachelor Program in Current Universities
}

\section{C.L.LI}

Electrical Engineering \& Automation Department, Shanghai Maritime University, Shanghai 201306, China

\section{R.Y.ZHAO}

CIMS Research Center, School of Electronics and Information Engineering, Tongji University, Shanghai 201804, China

\begin{abstract}
In current universities, professional English course for students majored in automation of bachelor degree program is playing an increasing important role for training to master the international academic and the latest developments in automation industries. Inevitably, some obvious problems emerge in the teaching and study around professional English course. This paper analyzes the characteristics of professional English course for automation bachelor degree, discovers current problems, and further lists three most effecting problems after a full investigation. These problems are the lack of new teaching materials, the fuzzy cognition of the students, the insufficient staff training. This paper proposes a novel teaching strategy to solve these problems, consisting of re-adjustment teaching goals, activating student and staff training. Finally the experimental results from a volunteer class verify the high-efficiency of this novel teaching strategy proposed in this paper.
\end{abstract}

KEYWORD: Professional English; Teaching Strategy; Automation Major;

\section{INTRODUCTION}

Professional English course for students majored in automation of bachelor degree program(PECA) is a course in designed after public English courses, aims to guide students to read the science and technology articles, and raise the understanding ability, translation ability, writing ability in the professional English materials and references around the area of automation industries. Thereby this course can build a sound foundation in the international usage for the students majored in automation on campus (Bundy 2014, Correa, 2014, Correa, 2014).

\section{CHARACTERISTICS OF PROFESSIONAL ENGLISH FOR AUTOMATION}

\subsection{Easy-confusing polysemy}

There are lots of polysemy words in English language. Automation professional English is different from public English at the aspects of the characteristics and meaning of word. The same word in daily life may have different meanings in different area. For example, the word "base", its basic meaning is refers to the "basis", but in the machinery area, it refers to the "base body", in the chemical industry it refers to the "alkali ", in the geometric triangle refers to "the bottom" (Dalton 2014, Davis 2014, El-Jardali, 2014). Therefore the simple judgment and translation of the polysemy words will possibly not only make jokes, more serious and may be an accident in engineering areas.

\subsection{Structural diversity}

The English science and technology articles own quite characteristics themselves with the diverse sentence structures. Typically, these characteristics are the long sentences, passive sentence, lots of nominalization structure respectively. All these characters bring difficulties in understanding and translation of the original text (Lyon 2014, McIntosh 2014). These difficulties usually can be solved in public English with the traditional teaching strategies. This fact increases the difficulty of teaching and learning for professional English course for students majored in automation of bachelor degree program.

\subsection{Abstract theory}

One of the most obvious characteristics of the professional English course for automation major is 
that it is related to abstract theory especially used in automation area. The wording is stiff, with rigorous sentences, easy-boring (Ogrinc 2014, VandenBoom 2014).

The professional automation English articles are rigid-logical with coherent meaning; they are smooth and clear in the article structure; these articles state accurately and objectively; the description is standard; the paragraph tone is formal; the reasoning and judgment is strict in logic.

When reading and translating professional English articles first time, most students have been used to translate according to the sentence order and grammar structure, being lack of translation skills of understanding, easily to write disconnected or unclear. This fact makes the students confused in understanding these original English articles in professional automation English.

\section{PROBLEMS IN TEACHING AND STUDY}

With the characteristics analysis for professional English course for automation bachelor degree, we discover current problems and further list three most obvious problems after a full investigation. These problems are the lack of new teaching materials, the fuzzy cognition of the students, the insufficient management as follows.

\subsection{Lack of new teaching materials}

Professional English teaching material arranged only according to the program of automation major. Thereby the existing teaching materials basically are extracted from some original English textbooks or the scientific or technical articles without appropriate rearrangement and edition in the course of professional automation English. This fact leads to the low logic and coherence in the content arrangement (Ogrinc 2014, Waits 2014). Even some content comes from a part of specification or a manual of an automatic device, a controlling system. Students feel it boring to study these contents without sufficient preparation of the background. It is too difficult for the teacher to arrange a real discussion about some topic around the content which is being studied on.

\subsection{Fuzzy cognition of the students}

There exists the fuzzy cognition of students on this course. They misunderstand that professional automation English is just an optional course not compulsory. They think that it is easy to pass this course only depending on the remembering of the professional vocabulary, which makes a negative influence during the study of professional English course for automation bachelor degree.

The professional automation English course is generally arranged in the first semester of the third academic year for the students majored in automation. In the stage, the students just finish the basic courses of study, with the further study of major courses. These students also begin to gradually strengthen the professional knowledge and skills since this semester. While being lack of understanding of the professional background, knowledge and prospects, and professional English and professional course is not synchronous learning, the students majored in automation usually feel difficult to understand the new content of the professional English consequently. Further some students feel fear to use common and public English describes the content in professional English. They become lack of lack of learning motivation and interest gradually.

On the other hand, the students who did not pass the CET-4 (College English Test Band 4) examination are lack of the confidence, which generates the passive and direct impact on learning professional English further.

\subsection{Insufficient staff training}

There is insufficient in the staff training for the teachers who teach the professional automation English course. Current professional automation English teachers are majored in the automation. They know the professional knowledge very well. But they are lack of professional teaching training in English, which leads directly to usage of traditional teaching method. Teaching means are single. Teaching form is boring. This fact reduces the ability to stimulate students' interest in learning professional automation English. Therefore the teachers need more training around the teaching methods, discussion organization, advanced estimation methods.

\section{IMPROVEMENT STRATEGY}

Based on the characteristic analysis and problem discussion above, we propose an novel teaching strategy in the course of professional English course for automation bachelor degree. This strategy consists of re-adjustment teaching goal, activating student interest and staff training, shown in Figure 1. 


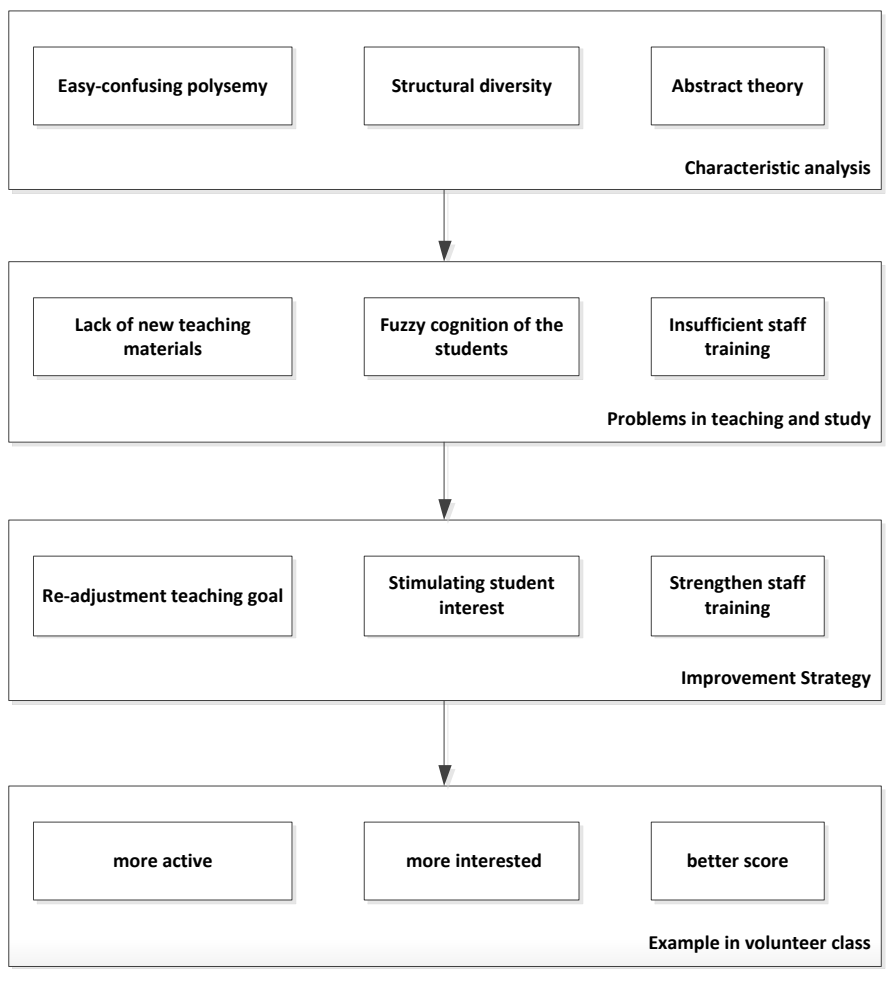

Figure 1.Improvement strategy for the PECA .

\subsection{Re-adjustment teaching goal}

Professional English teaching material arranged only according to the program of automation major. Thereby the existing teaching materials basically are extracted from some original English textbooks or the scientific or technical articles without appropriate rearrangement and edition in the course of professional automation English. This fact leads to the low logic and coherence in the content arrangement. Even some content comes from a part of specification or a manual of an automatic device, a controlling system. Students feel it boring to study these contents without sufficient preparation of the background. It is too difficult for the teacher to the teaching goal of professional automation course should be re-adjusted according to the features and services target of automation major, combined with three levels of teaching requirements announced by the National Ministry of Education about "university English teaching requirements". The specific course goals are

1) master $600-900$ professional vocabularies in automation area;

2) basic understanding with listening content in professional English;

3) fluent and clear speaking, can exchange professional topic in English;

4) read and understand the professional materials in English;

5) write with the professional documents in English;
6) use appropriate translation techniques, to translate between professional English and profession Chinese in automation area.

There should exist different emphases the above six goals during the professional automation English teaching. The most important goals are the "reading" and "translation".

\subsection{Activating student}

In order to activate the student on the class, the teacher in this course should strengthen the students' cognition of the importance of the course. He can introduce the importance of professional automation English from study overseas, work in foreign-funded enterprises, making students understand that mastering professional English is the foundation to master professional field of new knowledge.

The teacher can make students' cognition clear and deep by guiding students to consult the relevant professional English literature, scientific information on the internet, or listen to a MIT public class, thus stimulating the students' interest in learning the course of professional automation English.

\subsection{Strengthen staff training}

The administration department should increase and strengthen staff training to improve the method of teachers. With the professional training, teachers can timely enrich and renew the teaching content, adopting the advanced teaching methods and means, such as multimedia teaching, animation and vivid video teaching according the specific teaching program in the course of professional automation English.

\section{EXAMPLE IN VOLUNTEER CLASS}

In order to verify the positive effect possibly generated by this novel teaching improvement strategy proposed in this paper. We organize an experiment class consisting of volunteers. All the volunteers are the junior students who are studying in the course of professional English for automation major in a university. The data of class organization, student number, CET-4 score as the common English ability, reference, the midterm examination, the final examination, and the discussion in group are recorded and analyzed respectively. All the data shows that the students are more active on class, more interested in the content of this improved professional automation English course with a better score finally. The teacher also learn from his teaching in this course. 


\section{CONCLUSIONS}

There inevitably exist some big issues in the professional English course for students majored in automation of bachelor degree program. With reasonable method, all the possible causes leading to the problems can be discovered and analyzed respectively. Further, this paper proposes a novel improvement strategy to solve the current problems.

In the future, the research on the improvement of the teaching for the course of professional English for students majored in automation should be implemented further with the development of the major course program.

\section{ACKNOWLEDGEMENTS}

This work is supported by Shanghai Maritime University research practice project (Grant No.2014 A1-5201-14-0105X), the National Natural Science Foundation of China (Grant No. 71373178) and Natural Science Foundation of Shanghai, China (Grant No. 13ZR1444700). Thanks the work of Professor Rongyong Zhao as the corresponding author (zhaorongyong@tongji.edu.cn).

\section{REFERENCES}

[1] Bundy, D. G., Morawski, L. F., Lazorick, S., et al.. 2014. Education in Quality Improvement for Pediatric Practice: An Online Program to Teach Clinicians QI. Academic Pediatrics, 14(5): 517-525.
[2] Correa, M. 2014. Teaching (Theoretical) Linguistics in the Second Language Classroom: Beyond Language Improvement. Porta Linguarum(22): 161-171.

[3] Dalton, S. 2014. THE RACP AND NSW CLINICAL EXCELLENCE COMMISSION: TEACHING CLINICAL PRACTICE IMPROVEMENT TO ADVANCED TRAINEES. Internal Medicine Journal, 44: 13-13.

[4] Davis, N. L., Davis, D. A., \& Rayburn, W. F. 2014. Clinical faculty: taking the lead in teaching quality improvement and patient safety. American Journal of Obstetrics and Gynecology, 211(3): 215-U671.

[5] El-Jardali, F., Sheikh, F., Garcia, N. A., Jamal, D., \& Abdo, A. 2014. Patient safety culture in a large teaching hospital in Riyadh: baseline assessment, comparative analysis and opportunities for improvement. Bmc Health Services Research, 14.

[6] Lyon, H. C., Jr., Holzer, M., Reincke, M., Brendel, T., Ring, J., Weindl, A., Zottmann, J. M., \& Fischer, M. R. 2014. Improvements in teaching behavior at two German medical schools resulting from a modified Flanders interaction analysis feedback intervention process. Medical Teacher, 36(10): 903-911.

[7] McIntosh, G. N., Schwartz, N., Bishop, S., Brooks, M. N., \& Lee, B. 2014. TEACHING QUALITY IMPROVEMENT USING A CASE-BASED LEARNING FORMAT. Journal of General Internal Medicine, 29: S536-S536.

[8] Ogrinc, G. 2014. Teaching quality improvement and health care systems at Dartmouth's Geisel School of Medicine. The virtual mentor: VM, 16(2): 108-110.

[9] VandenBoom, T., Chen, H., Gamez, R., Pambuccian, S., \& Yong, S. 2014. Resident Learning in Gastrointestinal Pathology: Opportunities for Teaching Improvement. Laboratory Investigation, 94: 150A-150A.

[10] Waits, S. A., Reames, B. N., Krell, R. W., Bryner, B., Shih, T., Obi, A. T., Henke, P. K., Minter, R. M., Englesbe, M. J., \& Wong, S. L. 2014. Development of Team Action Projects in Surgery (TAPS): A Multilevel Team-Based Approach to Teaching Quality Improvement. Journal of Surgical Education, 71(2): 166-168. 